\title{
Hoarseness and Laryngopharyngeal Reflux: A Prospective Study
}

\author{
Ahamed Nauphal Pullarat ${ }^{1}$, Anoop Attakkil ${ }^{2}$, Sibin. M.A ${ }^{3}$, \\ Deepak Ranjan Nayak ${ }^{4}$, Suresh Pillai ${ }^{5}$ \\ ${ }^{I}$ Assistant Professor, Department Of ENT, MES Medical College, Perinthalmannamalappuram, Kerala, India \\ ${ }^{2}$ Senior Resident, Department Of ENT, MES Medical College, Perinthalmannamalappuram, Kerala, India \\ ${ }^{3}$ Department Of ENT, Kasturba Medical College, Manipal, Manipal University, Karnataka, India \\ ${ }^{4}$ Associate Professor, Department Of ENT, Kasturba Medical College, Manipal, Manipal University, \\ Karnataka, India \\ ${ }^{5}$ Associate Professor, Department Of ENT, Kasturba Medical College, Manipal, Manipal University,
} Karnataka, India

\begin{abstract}
Introduction: Laryngopharyngeal reflux (LPR) is a well prevalent disease which has been evaluated as an important cause of voice disorder. We aimed to to assess the causal relationship of hoarseness to laryngopharyngeal reflux and to evaluate the efficacy of treatment of those with hoarseness due to laryngopharyngeal reflux with antireflux measures

Materials and Methods: Thirty patients who presented with hoarseness and symptoms suggestive of laryngopharyngeal reflux excluding other causes were evaluated. Reflux symptom index (RSI), Reflux finding score (RFS), Objective voice assessment using Multi Dimensional Voice Profile (MDVP) software measuring acoustic parameters such as Jitter, Shimmer and Harmonic-Noise ratio were assessed at baseline and after two months post-therapy where they were treated with pantoprazole $40 \mathrm{mg}$ once daily for 2 months. Statistical analysis was performed using Statistical Package for the Social Sciences (SPSS).

Results: The study included 30 patients with hoarseness with a majority of them in 31-40 age group and $67 \%$ of patients were female. The mean RSI score pre treatment was $17.3 \pm 2.5 S D$ and post treatment it was $6.5 \pm 2.22$ $S D$ with ' $p$ ' value(<0.01). All patients had congested arytenoids(100\%) while majority (66.67\%) also had posterior commissure hypertrophy and vocal fold oedema. The mean RFS pre treatment was $6.56 \pm 1.8$ SD and post treatment it was $2.4 \pm 1.61$ SD with clinically significant ' $p$ 'value (<0.001 ). The mean shimmer value pre treatment was $2.9 \pm 0.71 S D$ and post treatment it was $1.12 \pm 0.22 \mathrm{SD}$. ' $p$ ' value (0.01).The mean HNR value pre treatment was $0.19 \pm 0.03 S D$ and post treatment it was $0.15 \pm 0.03$ SD with ' $p$ ' value (0.08) which was not clinically significant.

Conclusions: Laryngopharyngeal reflux has to be considered as one of the causes in patients with hoarseness. Reflux symptom index, Reflux finding score and Objective voice analysis are effective indicators of therapeutic efficacy. We also found that there is causal association of hoarseness to laryngopharyngeal reflux as all our patients symptomatically improved with antireflux measures. We conclude that empirical trial of PPI for a period of 2 mths is an effective initial diagnostic tool for laryngopharyngeal reflux as well as the treatment. We found that all our results were comparable to other similar studies.
\end{abstract}

\section{Introduction}

Laryngopharyngeal Reflux is the retrograde movement of gastric contents above the upper oesophageal sphincter into the larynx, pharynx and upper aero digestive tract, causing pharyngeal and/or laryngeal symptoms. While the prevalence of reflux-related otolaryngologic symptoms and findings in otolaryngology practice has been estimated as four to 10 per cent, the prevalence of reflux in patients with voice disorders may be as high as 50 per cent. Early research by Delahunty and Cherry[1] found that inflammation, ulceration, and the formation of granulation tissue on the vocal fold mucosa followed extended exposure to gastric material. Of all of the causes of laryngeal inflammation, gastroesophageal reflux disease (GER, GERD) is the most common cause, and as many as 10 to $50 \%$ of patients with laryngeal complaints have a GER-related underlying cause.[2,3]. Laryngopharyngeal reflux affects both children and adults and may be associated with an acute, chronic, or intermittent pattern of laryngitis, with or without granuloma formation. Indeed, LPR has also been implicated in the development of laryngeal carcinoma and stenosis, recurrent laryngospasm, and cricoarytenoid joint fixation, as well as with many other otolaryngology-related conditions, including globus pharyngeus, cervical dysphagia, and subglottic stenosis.[4-9]. Patients with "reflux laryngitis" (LPR) present with hoarseness, but almost two thirds deny ever having heartburn.[3-6].

In a retrospective review of 216 patients with cervical symptoms that were believed to be associated with EER, Rival and colleagues found that the most frequent complaint was cervical dysphagia (33\%), followed 
by globus (19\%), sore throat (17\%), and chronic throat clearing (14\%). The researchers found that $66 \%$ of these patients complained of classic symptoms of GERD such as acid regurgitation and heartburn.[10] Koufman et al [3] in his large series reported hoarseness as the commonest symptom(71\%), followed by c/c cough(51\%), globus pharyngeus $(47 \%)$ and c/c throat clearing. Ossakow et al compared the symptoms and findings of reflux disease in two discrete groups of patients(ENT and gastroenterology). They reported that hoarseness was present in $100 \%$ of ENT patients and $0 \%$ of GI patients.

Direct physiologic measurement of acid in the esophagus by 24-hour esophageal $\mathrm{pH}$ monitoring is the gold standard for the diagnosis of GERD. Therapeutic response to antireflux medications has been widely accepted as the initial diagnostic strategy rather than the gold standard investigation 'ambulatory dual probe $24 \mathrm{hr} \mathrm{pH}$ monitoring'. $24 \mathrm{hr} \mathrm{pH}$ monitoring is mandatory in refractory cases and those with life threatening manifestations such as subglottic stenosis. The majority of clinicians depend on clinical symptoms and response to empirical therapy with proton pump inhibitors (PPI) to make the diagnosis .There is, therefore, a need for further studies to help plan a diagnostic strategy for this common condition.

Belafsky, Postma, and Koufman [11][12][13] developed the Reflux Symptom Index (RSI), a selfadministered survey of nine questions used to assess patients with EER. Normative data gathered by these authors support that an RSI of more than 10 is associated with a high likelihood of positive dual-channel $\mathrm{pH}$ probe study.[14] They prospectively evaluated 40 patients with EER documented by dual pH probe studies and two months of medical management( TABLE 1). The RSI was noted to show improvement before changes were seen in the physical examination.

Table 1 Reflux Symptom Index

\begin{tabular}{|c|c|c|c|c|c|c|}
\hline \multicolumn{7}{|l|}{ The reflux symptom index } \\
\hline \multirow{2}{*}{$\begin{array}{l}\text { Within the past month, how did the following problems affect you? } \\
\text { Hoarseness or a prablem with your voice }\end{array}$} & \multicolumn{6}{|c|}{$\begin{array}{l}0=\text { No problem } \\
5=\text { Severe problem }\end{array}$} \\
\hline & 0 & 1 & 2 & 3 & 4 & 5 \\
\hline \multirow{8}{*}{$\begin{array}{l}\text { Clearing your throat } \\
\text { Excess throat mucue or postnasal drip } \\
\text { Difficulty swallowing food, liquids, or pills } \\
\text { Coughing after you ate or after lying down } \\
\text { Breathing difficulties or choking episodes } \\
\text { Troublesome or annoying cough } \\
\text { Sensations of something aticking in your throat or a lump in your throat } \\
\text { Heartburn, chest pain, indigestion, or stomach acid coming up }\end{array}$} & 0 & 1 & 2 & 3 & 4 & 5 \\
\hline & 0 & 1 & 2 & 3 & 4 & 5 \\
\hline & 0 & 1 & 2 & 3 & 4 & 5 \\
\hline & 0 & 1 & 2 & 3 & 4 & 5 \\
\hline & o & 1 & 2 & 3 & 4 & 5 \\
\hline & 0 & 1 & 2 & 3 & 4 & 5 \\
\hline & 0 & 1 & 2 & 3 & 4 & 5 \\
\hline & 0 & 1 & 2 & 3 & 4 & 5 \\
\hline & \multicolumn{5}{|c|}{ Total } & \\
\hline
\end{tabular}

Belafsky and colleagues have developed an endoscopic grading scale for EER. The Reflux Finding Score (RFS) is made up of eight findings that are graded on severity and that yield a score from 0 to 26 ( TABLE 2). The authors report that an RFS of more than seven is associated with a high likelihood of dual $\mathrm{pH}$ probe positivity.[14]

Table 5 Reflux Finding Score

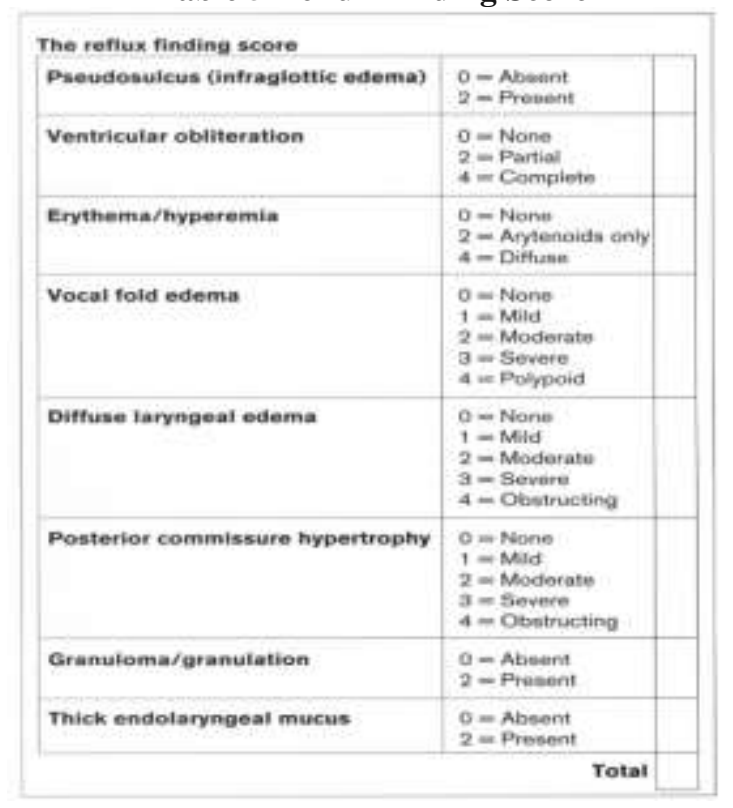


LPR disease has been the subject of several case control studies, which have concluded that a significantly lower voice quality (subjective and objective assessments) in LPR patients compared to controls. The aims of this study were (a) To assess the causal relationship of hoarseness to laryngopharyngeal reflux (b)To effectively treat those with hoarseness due to laryngopharyngeal reflux with antireflux measures and evaluate the response.

\section{Materials And Methods}

This was a prospective, cross-sectional study conducted in the Department of ENT, Head and Neck Surgery, Kasturba Medical College, Manipal over a period of one year. The study population consisted of 30 patients aged 20 years or above who came to our outpatient clinics with a history of change in the voice for more than 3 weeks and symptoms suggestive of laryngopharyngeal reflux. Patients with chronic pulmonary disease, asthma, heart disease, scleroderma, pregnant women, laryngeal papillomatosis, carcinoma larynx, vocal cord palsy, hypothyroidism, radiotherapy to neck, neurological deficits causing a change in the voice or those who had recently received antireflux drugs, and those allergic to any anesthetic agent were excluded from the study. As per proforma present and past history was taken with details of age, sex, profession, history of voice abuse, addiction, diet, and drug followed by general and ENT examination. Following this Reflux symptom questionnaire was handed over to them according to which they scored their symptoms. All patients were subjected to rigid angled telescopy of larynx(using Hopkin's 45degree nasal endoscope).Laryngeal findings were scored based on Reflux finding score. Objective voice assessment using Multi Dimensional Voice Profile (MDVP) software was done in Dept of Speech and hearing. Acoustic parameters such as Jitter, Shimmer and Harmonic-Noise ratio were measured. Following this patient was advised regarding Antireflux measures and was prescribed Antireflux medications - Pantoprazole 40mg OD for $2 \mathrm{mths}$. After 2 months, Reflux symptoms were scored again based on Reflux symptom questionnaire. Laryngeal findings were scored again based on Reflux findings index. Objective evaluation of voice was repeated. Values were entered in SPSS.

\section{Results}

\section{Age Groups}

Table 1

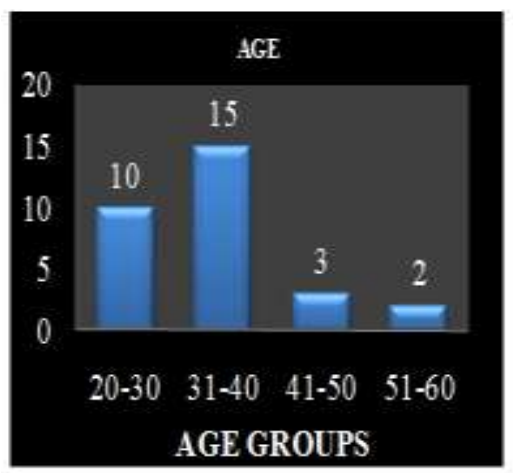

\begin{tabular}{|l|l|l|}
\hline $\begin{array}{l}\text { AGE } \\
\text { GROUP(YRS) }\end{array}$ & NUMBER & $\begin{array}{l}\text { PERCENTAGE } \\
(\%)\end{array}$ \\
\hline $20-30$ & 10 & 33.3 \\
\hline $31-40$ & 10 & 50 \\
\hline $41-50$ & 3 & 10 \\
\hline $51-60$ & 2 & 6.67 \\
\hline
\end{tabular}

Figure-1 : Majority of cases (50\%) were in the age group of 31-40 years

\section{Gender}

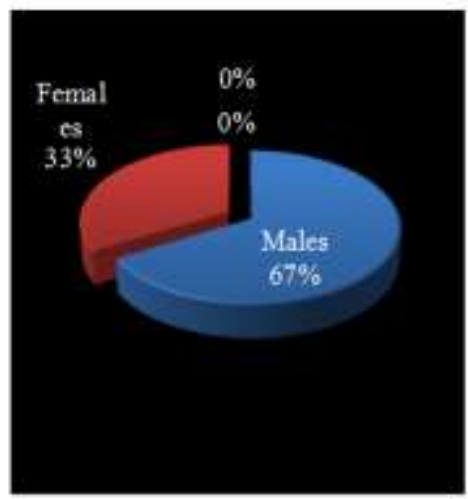

Table 2

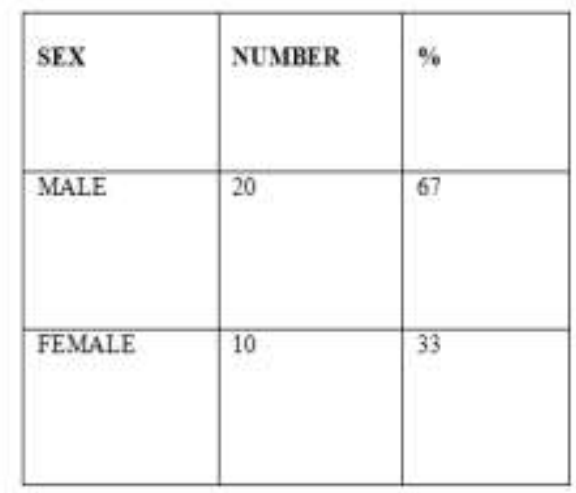

Figure- 2 Out of the 30 cases, $20(67 \%)$ were males and $10(33 \%)$ were females 


\section{Duration Of Illness}

Table 3
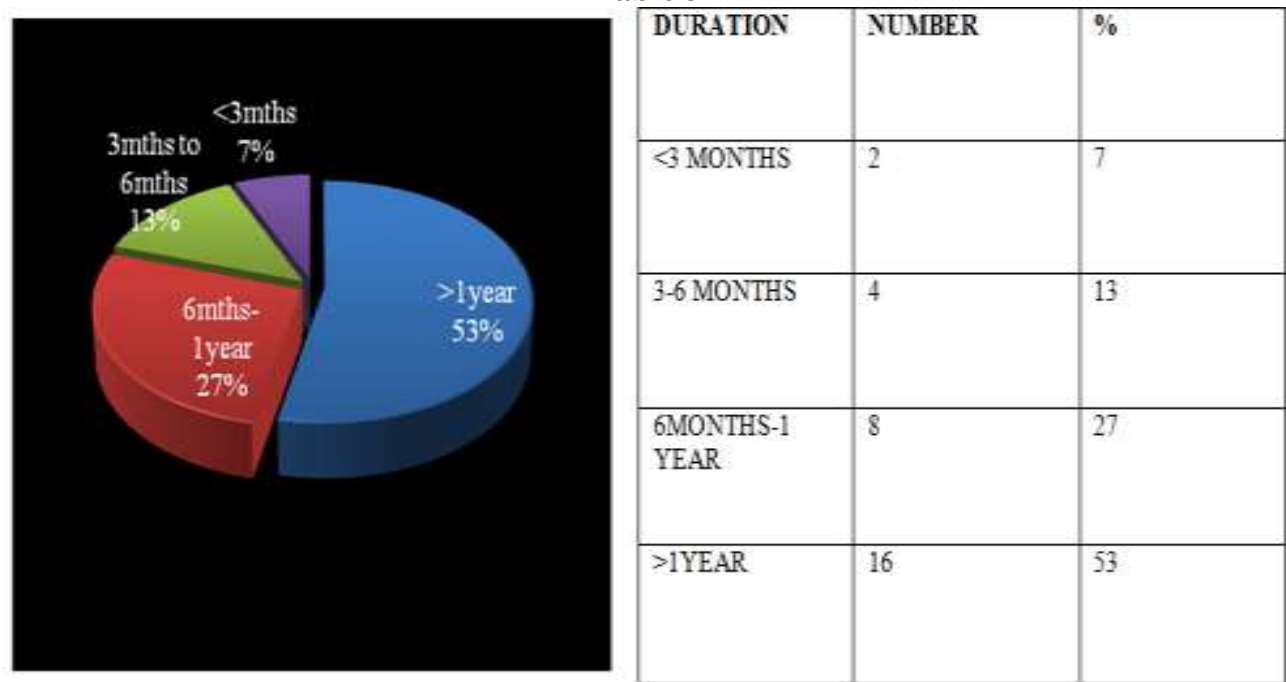

Figure-3 Majority (53\%) had a duration of illness lasting $>1$ yr while only $7 \%$ had a very short duration of $<3$ months

\section{Risk Factors}

Table 4

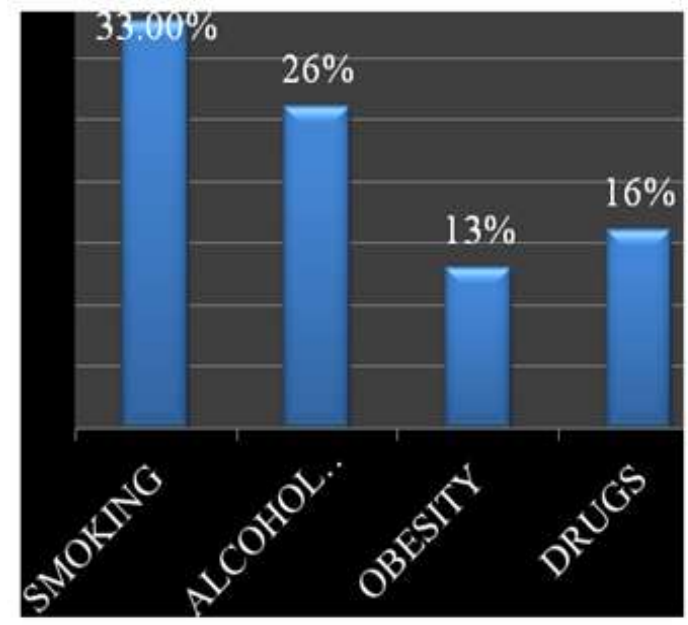

\begin{tabular}{|l|l|l|}
\hline RISK & NUMBER & $\%$ \\
\hline SACTORS & & \\
\hline Alcoholism & 8 & 33 \\
\hline Obesity & 4 & 13 \\
\hline Drugs & 5 & 16 \\
\hline
\end{tabular}

Figure- 4 Smoking (33\%) and alcoholism(26\%) were the major risk factors

\section{Associated Symptoms}

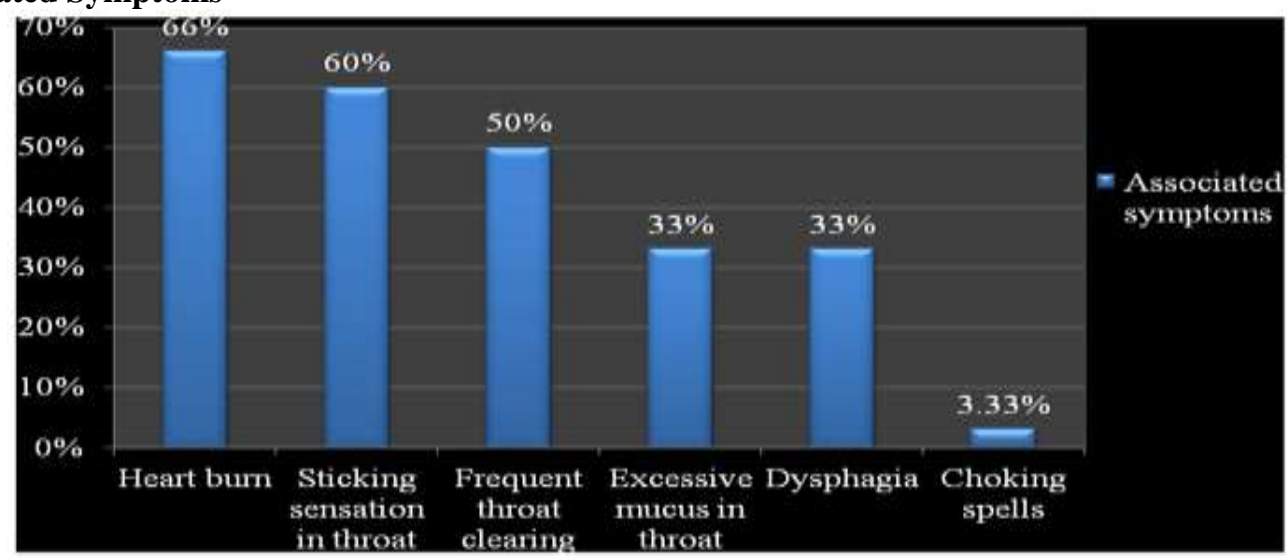

Figure- 5: Apart from hoarseness major symptoms were heartburn(66\%), sticking sensation in throat $(60 \%)$ and frequent throat clearing $(50 \%)$ 
Table 5

\begin{tabular}{|l|l|l|}
\hline Symptoms & Number & $\%$ \\
\hline Heart Burn & 20 & 66 \\
\hline Sticking Sensation In Throat & 18 & 60 \\
\hline Frequent Throat Clearing & 15 & 50 \\
\hline Excessive Mucus In Throat & 10 & 33 \\
\hline Dysphagia & 10 & 33 \\
\hline Choking Spells & 1 & 3.33 \\
\hline
\end{tabular}

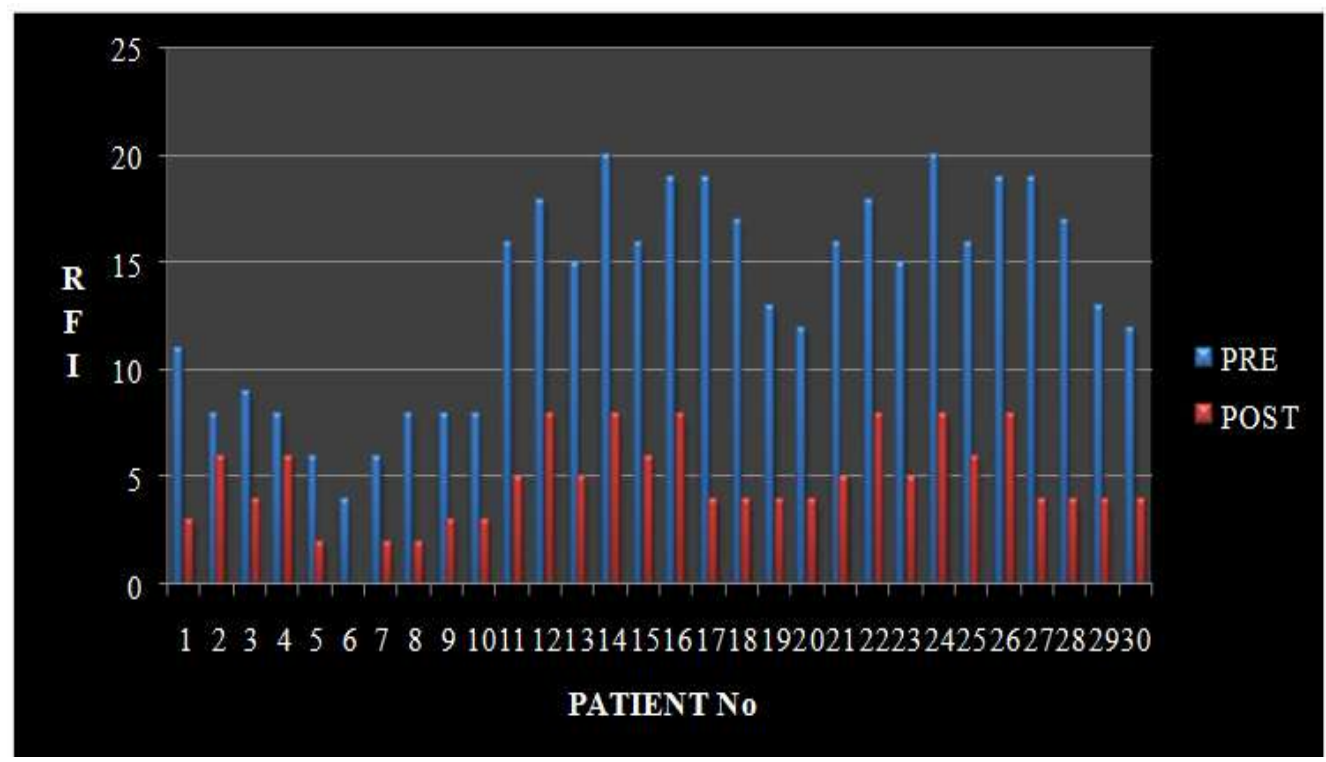

Figure- 6 :Reflux Symptom Index (Score 0-45, Patient No 1-30)

MEAN, SD and ' $p$ ' value for RSI

Table- 6

\begin{tabular}{|l|c|c|c|}
\hline & MEAN & SD & \multirow{2}{*}{ 'p' value } \\
\hline RSI pre & 17.3 & 2.49 & \multirow{2}{*}{0.01} \\
\cline { 1 - 3 } RSI post & 6.5 & 2.22 & \\
\hline
\end{tabular}

The mean RSI score pre treatment was $17.3 \pm 2.5 \mathrm{SD}$ and post treatment it was $6.5 \pm 2.22$ SD. 'p' value was 0.01 and it was clinically significant

\section{Laryngeal Findings}

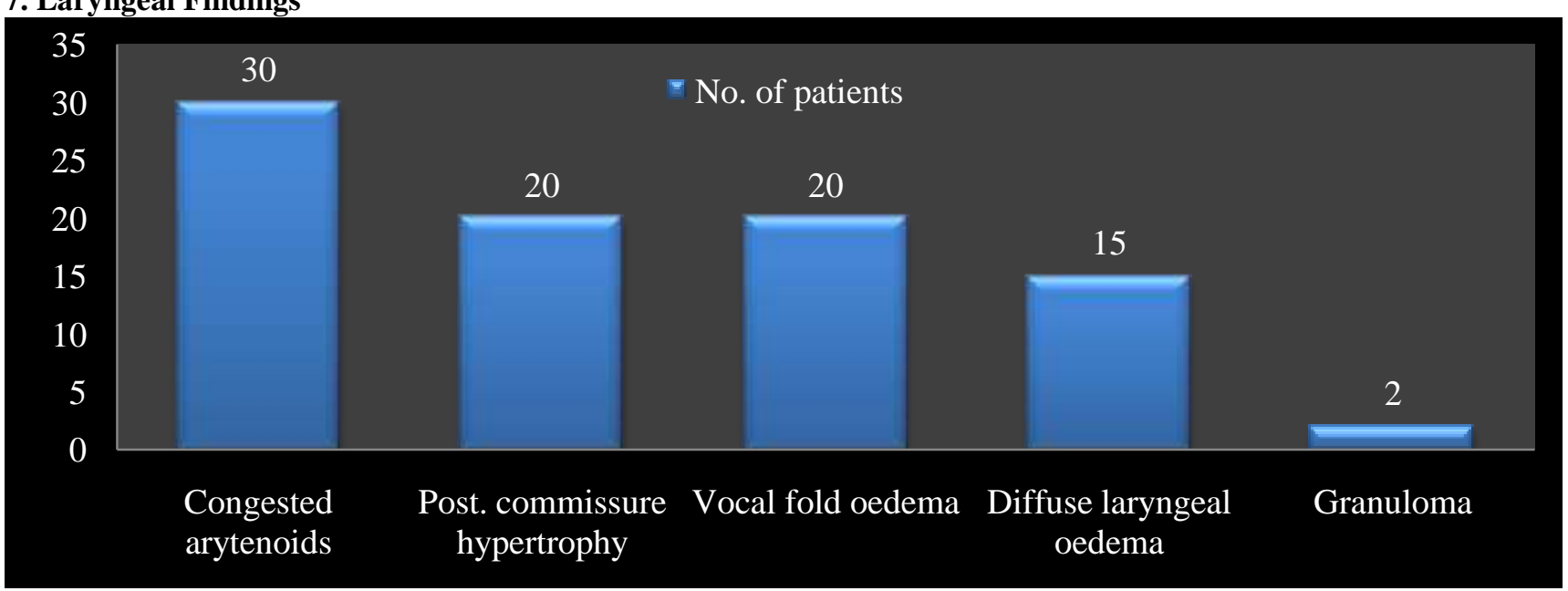

Figure- 7: All patients had congested arytenoids(100\%) while majority (66.67\%) also had posterior commissure hypertrophy and vocal fold oedema 
Table 7

\begin{tabular}{|l|l|l|}
\hline Laryngeal findings & Number & $\%$ \\
\hline Congested arytenoids & 30 & 100 \\
\hline Posterior commissure hypertrophy & 20 & 66.67 \\
\hline Vocal fold oedema & 20 & 66.67 \\
\hline Diffuse laryngeal oedema & 15 & 50 \\
\hline Granuloma & 2 & 6.67 \\
\hline
\end{tabular}

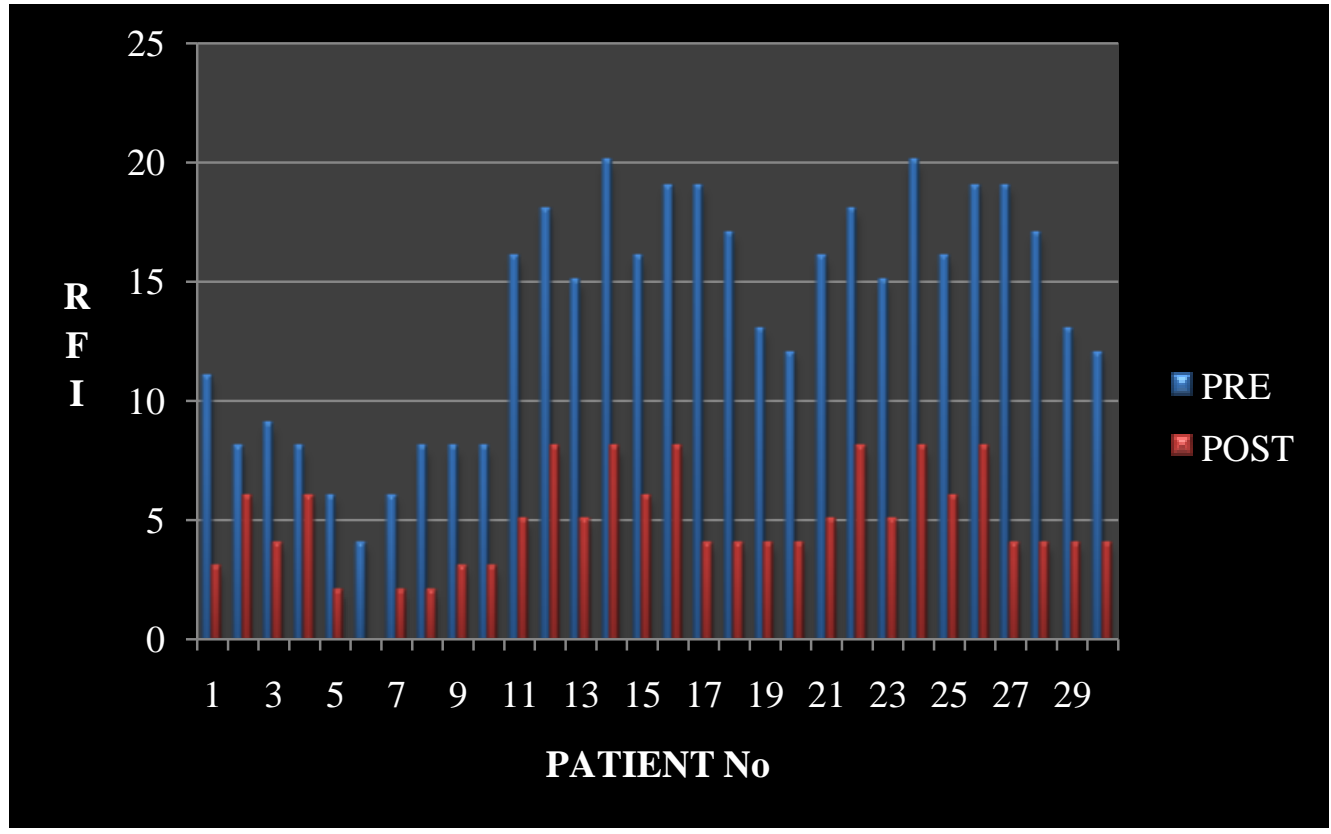

FIG 8. Refluxfinding Score (Score 0-26, Patient No 1-30)Mean, Sd And 'P' Value- Rfs

Table- 8

\begin{tabular}{|l|l|l|l|}
\hline & MEAN & SD & 'p' value \\
\hline RFS pre & 6.56 & 1.80 & \multirow{2}{*}{0.001} \\
\cline { 1 - 3 } RFS post & 2.40 & 1.61 & \\
\hline
\end{tabular}

The mean RFS pre treatment was $6.56 \pm 1.8 \mathrm{SD}$ and post treatment it was $2.4 \pm 1.61 \mathrm{SD}$. 'p' value was found to be 0.001 which is clinically significant.

Jitter(Table- 9)

\section{Objective Voice Analysis}

\begin{tabular}{|l|c|c|c|}
\hline & MEAN & SD & 'P' Value \\
\hline JITTER Pre & 0.48 & 0.03 & \multirow{2}{*}{0.03} \\
\hline JITTER Post & 0.27 & 0.06 & \\
\hline
\end{tabular}

The mean jitter value pre treatment was $0.48 \pm 0.03 \mathrm{SD}$ and post treatment it was $0.27 \pm 0.06 \mathrm{SD}$. 'p' value was found to be 0.03 which is clinically significant

Shimmer (Table- 10)

\begin{tabular}{|l|c|c|c|}
\hline & MEAN & SD & \multirow{2}{*}{ 'p'value } \\
\hline SHIMMER pre & 2.9 & 0.71 & \\
\cline { 1 - 2 } SHIMMER post & 1.12 & 0.22 & \multirow{2}{*}{0.01} \\
\hline
\end{tabular}

The mean shimmer value pre treatment was $2.9 \pm 0.71 \mathrm{SD}$ and post treatment it was $1.12 \pm 0.22 \mathrm{SD}$. 'p' value was found to be 0.01 which is clinically significant 
Noise-Hoarseness Ratio (Table- 11)

\begin{tabular}{|l|c|c|c|}
\hline & MEAN & SD & 'p' value \\
\hline NHR pre & 0.19 & 0.03 & \\
\cline { 1 - 2 } NHR post & 0.15 & 0.03 & 0.08 \\
\hline
\end{tabular}

The mean NHR value pre treatment was $0.19 \pm 0.03$ SD and post treatment it was $0.15 \pm 0.03$ SD. 'p' value was found to be 0.08 which is not clinically significant.

\section{Discussion}

The prevalence of reflux-related otolaryngologic symptoms and findings in otolaryngology practice has been estimated as four to 10 per cent. The prevalence of reflux in patients with voice disorders may be as high as 50 per cent.[3]

Our study group comprised of 30 patients who came to our hospital with hoarseness and with symptoms suggestive of laryngopharyngeal reflux. Majority of patients were males $(\mathrm{M}: \mathrm{F}=2: 1)$ and most were in the age group of 31-40yrs. Age group was $57 \pm 17 \mathrm{yrs}$ and males were $56 \%$ in Belafsky et al's study [2002][11] The duration of illness was in the range of $3 \mathrm{mths}$ to $2 \mathrm{yrs}$ with most of them (53\%) having symptoms for more than $1 \mathrm{yr}$

Apart from hoarseness major symptoms were heartburn(66\%), sticking sensation in throat(60\%), frequent throat clearing(50\%), excessive mucus in throat(33\%), dysphagia(33\%) and choking spells(3\%). Koufman et al[2001][15] in his large series reported hoarseness as the commonest symptom(71\%), followed by c/c cough(51\%), globus pharyngeus $(47 \%)$ and c/c throat clearing. Ossakow et al [1987][16] compared the symptoms and findings of reflux disease in two discrete groups of patients(ENT and gastroenterology). They reported that hoarseness was present in $100 \%$ of ENT patients and $0 \%$ of GI patients. But heartburn was present in $89 \%$ of GI patients and $6 \%$ of ENT patients. The reason for heartburn seen less in LPR patients according to them is the relative laryngeal hypersensitivity to reflux damage even if a patient does not have enough reflux to produce oesophagitis. However many of these symptoms are nonspecific and may be produced by other conditions such as smoking, allergies and post nasal drip

In our study , smoking (33\%) and alcoholism (26\%) were the major risk factors. The other ones were obesity (13\%) and drugs (16\%). In the review by Wong and Kinoshita,10 well-established risk factors for GERD in Asian populations included hiatal hernia and obesity. Age and sex (male) also may be risk factors. Rosaida and Goh reported that independent risk factors for reflux esophagitis were male gender, Indian race, presence of hiatal hernia, and alcohol consumption [17]

The mean RSI score pre treatment was $17.3 \pm 2.5 \mathrm{SD}$ and post treatment it was $6.5 \pm 2.22 \mathrm{SD}$ (p $<0.01)$. All the patients were relieved of the symptoms after $2 \mathrm{mths}$. In a study conducted by Jin et al [2008] the mean value of RSI was $8.55 \pm 4.22$ at pretreatment, which decreased significantly to $5.33 \pm 3.53,3.15 \pm$ $1.97,2.23 \pm 1.73$, and $1.21 \pm 1.44$ at the $2 \mathrm{nd}$, 4th, 8th and 12th weeks, respectively, after which no more significant improvement was observed. . Belafsky et al [2002] in their study had a mean RSI of $19.9 \pm 11.1$ and after the completion of 6 month period was $12.8 \pm 10$ ( $\mathrm{p}<.001)$. RSI > 13 was considered abnormal. They compared RSI with Voice Handicap Index and found that RSI was easily administered, reproducible and with excellent construct and criterion validity [18]. Dauer et al [2006][19] compared RSI with Supra Esophageal Reflux Questionnaire (SERQ). They demonstrated good to excellent concurrent validity and reproducibility with both RSI and SERQ although SERQ proved statistically better on several individual items.

\begin{tabular}{|l|l|l|l|}
\hline & Our study & Jin et al & Belafsky et al \\
\hline & & & \\
RSI pre & $17.3 \pm 2.5 \mathrm{SD}$ & $8.55 \pm 4.22$ & $19.9 \pm 11.1$ \\
\hline & After $2 \mathrm{mths}$ & After 2 months & After $6 \mathrm{mths}$ \\
RSI post & $6.5 \pm 2.22 \mathrm{SD}$ & $2.23 \pm 1.73 \mathrm{SD}$ & $12.8 \pm 10 \mathrm{SD}$ \\
\hline
\end{tabular}

As for the signs all patients had congested arytenoids (100\%) while majority (67\%) also had posterior commissure hypertrophy and vocal fold oedema followed by diffuse laryngeal oedema in $50 \%$ and granuloma in 6\%. The most common sign was pseudosulcus vocalis in Belafsky et al's study [2002][13]. As per studies (Hickson et al [2001][20], Belafsky et al [2002][14] the positive predictive value of pseudosulcus vocalis for LPR is 90\%. Qadeer et al [2005][21], Ahamed et al [2005][22] and Noordzig et al [2002][23] in their study found that arytenoids oedema and erythema were the most common findings(60\%) in LPR. According to Noordzig et al [2002] study none of the laryngeal signs correlated with LPR severity. However, the specificity of these findings for LPR diagnosis is questionable because an earlier study by Hicks et al [2002][24] found that 
up to $87 \%$ of healthy volunteers had at least one sign attributed to LPR. In a more recent study, Milstein et al [2005][21] found a similarly high percentage of healthy population having laryngeal abnormalities. Furthermore, they also found that the use of different endoscopic instruments resulted in significantly different laryngoscopic findings. There is also significant inter- and intra-observer variability in diagnosis of LPR according to studies conducted by Merati et al [2003][21] and Branski et al [2002][24]

In our study the mean RFS pre treatment was $6.56 \pm 1.8$ and post treatment it was $2.4 \pm 1.61$. 'p' value was found to be 0.001 which was significant. The mean RFS pre-treatment as per Belafsky et al (2002)[12)] was $11.5 \pm 5.2$. This score improved to $9.3 \pm 4.7$ at 2 months, $7.3 \pm 5.5$ at 4 months, and $6.1 \pm 5.2$ at 6 months of treatment $(P<.001)$. They also found that an individual with a RFS greater than 7 has LPR. It is easily administered, takes less than 1 minute to complete, and manifests excellent inter- and intraobserver reproducibility. Although each item on the RFS is entirely subjective, the overall finding score reliably documents improvement with antireflux therapy. [Belafsky et al 2002] [20]. Branski and colleagues [2002][25] demonstrated unacceptably high inter- and intra-observer variability with 5 blinded otolaryngologists who attempted to visually diagnose LPR, calling into question the validity of physical findings as a gold standard for the diagnosis of SER, particularly for research protocols.

\begin{tabular}{|c|c|c|}
\hline & Our study & Belafsky et al \\
\hline RFS pre & $6.56 \pm 1.8 \mathrm{SD}$ & $11.5 \pm 5.2 \mathrm{SD}$ \\
\hline RFS post & $\begin{array}{c}\text { After } 2 \text { months } \\
2.4 \pm 1.61 \mathrm{SD}\end{array}$ & $\begin{array}{c}\text { After } 6 \text { months } \\
6.1 \pm 5.2 \mathrm{SD}\end{array}$ \\
\hline
\end{tabular}

Even though $24 \mathrm{hr}$ ambulatory dual probe $\mathrm{pH}$ monitoring is considered the gold standard investigation for the diagnosis of LPR there is no consensus with respect to $\mathrm{pH}$ sensors, its position or the interpretation of results. [Postma 2000][26]. Also this test is expensive and can be uncomfortable to the patient. In all the published studies, the $\mathrm{pH}$-criteria that were used to define proximal reflux were the same as those used to define acid reflux at the LES, i.e. a decrease in $\mathrm{pH}<4$. Interestingly, Ulualp et al.[2000] [27] in their review investigates the effect of using a higher cut-off value $(\mathrm{pH}<5$ instead of $\mathrm{pH}<4)$ to define proximal reflux. They found that this might be more useful in identifying proximal reflux, as neutralising factors (upper airway secretions and saliva) may raise $\mathrm{pH}$-values. Vaezi et al [1997][28] concluded that proximal pH-metry has an excellent specificity (91\%) but a poor sensitivity (55\%). The use of a $\mathrm{pH}$ study as the initial diagnostic study is recommended in patients with more severe conditions possibly related to LPR, such as subglottic stenosis and severe laryngospasm [Delgaudio et al 2003].[29]

Acoustic analysis as per our studies The mean jitter value pre treatment was $0.48 \pm 0.03 \mathrm{SD}$ and post treatment it was $0.27 \pm 0.06 \mathrm{SD}$. 'p' value was found to be 0.03 which is significant. The mean shimmer value pre treatment was $2.9 \pm 0.71 \mathrm{SD}$ and post treatment it was $1.12 \pm 0.22 \mathrm{SD}$. 'p' value was found to be 0.01 which is significant. The mean NHR value pre treatment was $0.19 \pm 0.03 \mathrm{SD}$ and post treatment it was $0.15 \pm 0.03 \mathrm{SD}$. 'p' value was found to be 0.08 which is not significant. In a similar study by Jin et al [2008][30] the mean value of jitter decreased significantly from $0.48 \pm 0.50 \%$ at pretreatment to $0.27 \pm 0.13 \%$ at 1 to 2 months after treatment $(p<.031)$. At 3 to 4 months after treatment, the value was $0.27 \pm 0.16 \%$, which was not significantly different from the value 1 to 2 months after treatment, but was significantly lower than the pretreatment value, suggesting that treatment was being maintained effectively $(p<.025)$. Likewise, the mean value of shimmer was $2.40 \pm 1.87 \mathrm{~dB}$ at pretreatment, and decreased significantly to $1.66 \pm 0.83 \mathrm{~dB}$ at 1 to 2 months after treatment $(p<.032)$, maintaining the value of $1.64 \pm 1.12 \mathrm{~dB}$ at 3 to 4 months after treatment $(p<.037)$. The mean value of HNR was $25.00 \pm 7.34$ at pretreatment, increased significantly to $27.88 \pm 5.32$ at 1 to 2 months after treatment $(p<.015)$, and was relatively constant at $27.24 \pm 6.71$ at 3 to 4 months after treatment $(p<.047)$. Hanson et al [2000][31] had similar results but Hamden et al [2001] did not find any significant improvement in acoustic parameters post treatment.

\begin{tabular}{|c|c|c|c|}
\hline & & Our study & Jin et al \\
\hline & pre & $0.48 \pm 0.03 \mathrm{SD}$ & $0.48 \pm 0.50 \mathrm{SD}$ \\
\hline & oost & $0.27 \pm 0.06 \mathrm{SD}$ & $0.27 \pm 0.13 \mathrm{SD}$ \\
\hline Shimmer & pre & & \\
\hline & post & $1.12 \pm 0.22 \mathrm{SD}$ & $1.66 \pm 0.83 \mathrm{~dB}$ \\
\hline & ore & $\begin{array}{c}0.19 \pm 0.03 \mathrm{SD} \\
\text { NHR } \\
0.15 \pm 0.03 \mathrm{SD} .\end{array}$ & $\begin{array}{c}25.00 \pm 7.34 \mathrm{SD} \\
\mathrm{HNR} \\
27.88 \pm 5.32 \mathrm{SD}\end{array}$ \\
\hline
\end{tabular}


Therapeutic response to empiric therapy allows for both diagnosis and treatment of LPR and involves lifestyle modifications and the use of acid-suppressing medications namely PPIs [Hanson et al 1995][32]. We used proton pump inhibitors for a period of $2 \mathrm{mths}$ to which all of them responded well. In Delgaudio et al [2003][31]study, after 8 weeks of treatment, 63\% patients had a significant improvement in their symptom scores. Their study showed a statistically significant difference in the laryngeal examination score after 2 months of therapy with PPI. Belafsky et al [2001][11] in their study found that symptoms improved over 2 months of antireflux treatment but signs persisted. According to them and the Consensus Conference Report on LPR 1997, they recommend twice daily PPI for a minimum of 6mths for the resolution of laryngeal injury due to reflux. Postma et al [2002][33] classified LPR into minor, major and life threatening and devised a treatment protocol accordingly. Their initial treatment recommendation was lifestyle modification with $\mathrm{H}_{2}$ blocker and if required twice daily PPI for 6 months. In major and life threatening they recommend to start with PPI twice daily and $24 \mathrm{hr} \mathrm{pH}$ monitoring based on the treatment response they either increased the dose of PPI or tapered it when an $\mathrm{H}_{2}$ blocker will be used in weaning period. If still not responding after 2-4 months of such treatment they recommend laparoscopic fundoplication surgery. Laparoscopic fundoplication is found to be highly successful and with less morbidity compared to traditional approach.[Dallemegne 1998].[34]

\section{Conclusion}

Laryngopharyngeal reflux has to be considered as one of the causes in patients with hoarseness. As for the results majority of cases $(50 \%)$ were in the age group of 31-40 years. $20(67 \%)$ were males and $10(33 \%)$ were females. Smoking (33\%) and alcoholism(26\%) were the major risk factors. The mean RSI score pre treatment was $17.3 \pm 2.5 \mathrm{SD}$ and post treatment it was $6.5 \pm 2.22 \mathrm{SD}$. 'p' value was and it was clinically significant. All patients had congested arytenoids(100\%) while majority (66.67\%) also had posterior commissure hypertrophy and vocal fold oedema. The mean RFS pre treatment was $6.56 \pm 1.8 \mathrm{SD}$ and post treatment it was $2.4 \pm 1.61 \mathrm{SD}$. 'p' value was found to be 0.001 which was clinically significant. The mean shimmer value pre treatment was $2.9 \pm 0.71 \mathrm{SD}$ and post treatment it was $1.12 \pm 0.22 \mathrm{SD}$. 'p' value was found to be 0.01 which was clinically significant. The mean HNR value pre treatment was $0.19 \pm 0.03 \mathrm{SD}$ and post treatment it was $0.15 \pm 0.03 \mathrm{SD}$. 'p' value was found to be 0.08 which was not clinically significant. We found that all our results were comparable to other similar studies. We conclude that empirical trial of PPI for a period of $2 \mathrm{mths}$ is an effective initial diagnostic tool for laryngopharyngeal reflux. We also found that there is causal association of hoarseness to laryngopharyngeal reflux as all our patients symptomatically improved with antireflux measures. Reflux symptom index, Reflux finding score and Objective voice analysis are effective indicators of therapeutic efficacy. Therapeutic response to empiric therapy allows for both diagnosis and treatment of LPR.

\section{Bibliography}

[1]. Branski RC, Bhattacharyya N, Shapiro J: The reliability of the assessment of endoscopic laryngeal findings associated with laryngopharyngeal reflux disease, Laryngoscope 112:1019, 2002

[2]. Koufman JA. The otolaryngologic manifestations of gastroesophageal reflux disease (GERD). Laryngoscope 1991;101 Suppl 53:178.

[3]. Koufman JA, Amin MR, Panetti M. Prevalence of reflux in 113 consecutive patients with laryngeal and voice disorders. Otolaryngol Head Neck Surg 2000; 123:385-8.

[4]. Bain WM, Harrington JW, Thomas LE, et al. Head and neck manifestations of gastroesophageal reflux. Laryngoscope 1983;93:175-9.

[5]. Little FB, Koufman JA, Kohut RI, et al. Effect of gastric acid on the pathogenesis of subglottic stenosis. Ann Otol Rhinol Laryngol 1985;94:516-9.

[6]. Ossakow SJ, Elta G, Colturi T, et al. Esophageal reflux and dysmotility as the basis for persistent cervical symptoms.Ann Otol Rhinol Laryngol 1987;96:387-92.

[7]. Ward PH, Hanson DG. Reflux as an etiological factor of carcinoma of the laryngopharynx. Laryngoscopy 1988;98:1195-9.

[8]. Morrison MD. Is chronic gastroesophageal reflux a causative factor in glottic carcinoma? OtolaryngolHead Neck Surg 1988;99:370-3.

[9]. Burton DM, Pransky SM, Katz RM, et al. Pediatric airway manifestations of gastroesophageal reflux. Ann Otol Rhinol Laryngol 1992;101:742-9.

[10]. Rival R and others: Role of gastroesophageal reflux disease in patients with cervical symptoms, Otolaryngol Head Neck Surg $113: 364,1995$

[11]. Belafsky PC, Postma GN, Koufman JA: Laryngopharyngeal reflux symptoms improve before changes in physical findings, Laryngoscope 111:979, 2001.

[12]. Belafsky PC, Postma GN, Koufman JA: The validity and reliability of the reflux finding score (RFS), Laryngoscope 111:1313, 2001.

[13]. Belafsky PC and others: Symptoms and findings of laryngopharyngeal reflux, Ear Nose Throat J 81(suppl 2):10, 2002.

[14]. Belafsky PC, Postma GN, Koufman JA: The association between laryngeal pseudosulcus and laryngopharyngeal reflux, Otolaryngol Head Neck Surg 126:649, 2002. 
[15]. Koufman JA: The otolaryngologic manifestations of gastroesophageal reflux disease (GERD): a clinical investigation of 225 patients using ambulatory 24-pH monitoring and an experimental investigation of the role of acid and pepsin in the development of laryngeal injury, Laryngoscope 101:S1, 1991.

[16]. Ossakow.S.J, Elta. G, Colturi.T et al, Esophageal reflux and dysmotility as the basis for persistent cervical symptoms. Ann Otol Rhinol Laryngol 1987; 96: 387-92

[17]. Chang-Chun Lin, Ya-Yu Wang et al: Association of heartburn and laryngopharyngeal symptoms with endoscopic reflux esophagitis, smoking, and drinking; Otolaryngology-Head and Neck Surgery 2009; 141, 264-271

[18]. Belafsky PC, Postma GN, Koufman JA. Validity and reliability of the reflux symptom index (RSI). J Voice 2002;16:274 -7.

[19]. Dauer, Thompson et al: Supraesophageal Reflux: Validation of a Symptom Questionnaire ; Otolaryngology-Head and Neck Surgery (2006) 134, 73-80

[20]. Hickson.C, Simpson. C.B et al: Laryngeal pseudosulcus as a predictor of laryngopharyngeal reflux; Laryngoscope 2001; 111.17425

[21]. Mohammed A. Qadeer, Jason Swoger et al: Correlation between Symptoms and Laryngeal Signs in Laryngopharyngeal Reflux; Laryngoscope 115: November 2005, 1947-52

[22]. Ahmed T, Ableson TI, Hicks DM, et al. Chronic laryngitis associated with GERD: a large scale prospective assessment of differences in practice patterns between gastroenterologists and ENT physicians. Gastroenterology 2005;128:M1769.

[23]. Pieter Noordzij, Aliaa Khidr et al: Correlation of pH Probe-Measured Laryngopharyngeal Reflux With Symptoms and Signs of Reflux Laryngitis; Laryngoscope, 112:2192-2195, 2002

[24]. Hicks DM, Ours TM, Abelson TI, et al. The prevalence of hypopharynx findings associated with gastroesophageal reflux in normal volunteers. J Voice 2002; 16:564-579.

[25]. Branski RC, Bhattacharyya N, Shapiro J: The reliability of the assessment of endoscopic laryngeal findings associated with laryngopharyngeal reflux disease, Laryngoscope 112:1019, 2002

[26]. Postma GN. Ambulatory pH monitoring methodology. Ann Otol Rhinol Laryngol Suppl 2000;184:10-14.

[27]. Ulualp SO, Toohill RJ: Laryngopharyngeal reflux: state of the art diagnosis and treatment, Otolaryngol Clin North Am 4:785, 2000.

[28]. Vaezi MF, Schroeder PL, Richter JE. Reproducibility of proximal probe pH parameters in 24-hour ambulatory esophageal pH monitoring. Am J Gastroenterol 1997;92:825-9.

[29]. John M. DelGaudio, J. Patrick Waring : Empiric Esomeprazole in the Treatment of Laryngopharyngeal Reflux; Laryngoscope, $113: 598-601,2003$

[30]. Bong Joon Jin, Yong Seop Lee et al: Change of Acoustic Parameters Before and After Treatment in Laryngopharyngeal Reflux Patients; Laryngoscope 118:May,938, 2008

[31]. Hanson DG and others: Acoustic measurements of change in voice quality with treatment for chronic posterior laryngitis, Ann Otol Rhinol Laryngol 106:279, 1997.

[32]. Hanson DG, Kamel PL, Kahrilas PJ: Outcomes of antireflux therapy for the treatment of chronic laryngitis, Ann Otol Rhinol Laryngol 104:550, 1995.

[33]. Postma, G.N., Johnson, L.F., Koufman, J. A.: Treatment of laryngopharyngeal reflux, ENT 81(S2):24, 2002

[34]. Lindstrom DR and others: Nissen fundoplication surgery for extraesophageal manifestations of gastroesophageal reflux (EER), Laryngoscope 112:1762, 2002. 